UDC 821.111.09-31 Џojc Џ.

\title{
Zoran Paunović
}

University of Belgrade, Serbia

\section{LEOPOLD BLOOM'S MEAGRE MEAL: FOOD AS METAPHOR IN JOYCE'S ULYSSES}

\begin{abstract}
In the intricate web of intertwined metaphorical meanings that constitute the overall multi-layered significance of Joyce's Ulysses, metaphorical aspects of food have a very prominent function in the novel. The paper deals with those aspects, mainly through brief analysis of Leopold Bloom's attitudes towards food. Bloom, the protagonist of Ulysses, has several meals in the course of the novel - each of them marked by different, complex feelings and different metaphorical meanings. The paper explores these meanings, especially those that are connected with themes of sexuality and marriage.
\end{abstract}

Although notorious for his sometimes appallingly ingenious acts of cruelty towards his characters, James Joyce was always very meticulous and considerate in the matters of their nutrition: from the festive dinner in 'The Dead', through the similarly bountiful Christmas gathering in A Portrait of the Artist as a Young Man, to late-night meals in Finnegans Wake, Joyce's characters consume vast amounts of food. It is no wonder, then, that food is one of the last strongholds in the life of Leopold Bloom, the protagonist of Ulysses. His life indeed is 'out of joint', seemingly for good, but in spite of all the details that suggest its disorder and chaos, it is still characterized by commendable eating habits and regular meals. It is quite obvious on June $16^{\text {th }} 1904$ : even in his tragicomical odyssey, during aimless wanderings through Dublin, fuelled not by yearning to come back home as soon as possible, but by the wish to stay outside his so-called home for as long as possible, he finds temporary shelters in the modest rituals of breakfast, lunch and dinner. It is, in fact, in the kitchen that we meet him for the first time, while he is preparing his only non-exilian meal on that day. Quite accordingly, the first facts we get to know about him deal with his gastronomic inclinations: 
Mr. Leopold Bloom ate with relish the inner organs of beasts and fowls. He liked thick giblet soup, nutty gizzards, a stuffed roast heart, liver slices fried with crustcrumbs, fried hencods' roes. Most of all he liked grilled mutton kidneys which gave to his palate a fine tang of faintly scented urine. ${ }^{1}$

Such a detailed list of Bloom's favourite meals constitutes a strong physical counterbalance to the metaphysical elevations of Stephen Dedalus who in the previous three chapters, hindered by the gigantic wings of his artistic ambitions, with painstaking effort and true disgust tries to walk on solid ground. Bloom, on the other hand, yearns for those heights where the inscrutable beauty of Wagner's harmonies and Shakespeare's verses reign, but he stands firmly on the ground with both his feet: the best proof of that is provided by his belly. That is why, quite appropriately, in his kitchen he does not think about Renaissance drama or German classical opera, but about kidneys. His considerably neglected body, for quite a number of years deprived of pleasure in his marriage bed (as well as in all the other beds), finds relief in his imagination, in which sexual fantasies are often connected with food. Symbolically and literally, in the fourth episode it is most strikingly shown during the scene in the butcher shop, where Bloom admires the 'hams' of an appealing young woman from his neighbourhood, so much so that upon leaving the shop he adjusts his step to hers, so that he can enjoy the sight for a little longer. Bloom's ensuing breakfast - when kidneys from his mind materialize first in the frying pan and then on the plate - will be almost as glorious as his voyeuristic experience.

His lunch, however, will be far less spectacular. That modest meal will provide a symbolical counterpart of his devastated marriage: it amounts to a glass of Burgundy wine and a gorgonzola sandwich. It is the meal of a man who eats not with an ambition to enjoy his food, but with an aim to satiate his hunger; it is a meal that should help him function through several hours between equally tedious tasks of breakfast and dinner.

It is, therefore, at the time of lunch that we discover Bloom's new attitude towards food, rather unexpected after what we have witnessed at his breakfast: he loathes it. He loathes food, just as he loathes his marital life, which in fact expelled him to the street where he is to spend his June $16^{\text {th }}$ from morning till night, in order to leave as much time as possible to his unfaithful wife Molly to have a sexual encounter with her lover, and as little time as possible to himself to think about her adultery. In accordance

${ }^{1}$ James Joyce, Ulysses, Oxford University Press, 1993, Oxford, p. 53. 
with that, in Joyce's system of structural and essential parallels with Homer, the episode centered by Bloom's lunch (Episode 8), corresponds with the story about the Lestrygonians in Homer's Odyssey. The Lestrygonians are cannibals, ${ }^{2}$ and that fact symbolically suggests the reasons for Bloom's negative attitude towards food. Food is here also closely connected with sexuality - this time in the negative context of Molly's adultery. It is not yet clear who will eat whom in that marriage triangle - but Bloom is the one who feels sick in advance.

That sickness is present from the very beginning of the episode, when with certain disgust Bloom watches a 'sugarsticky girl shoveling scoopfuls of creams for a christian brother' (144). Then in his characteristically unpredictable manner he thinks about 'lozenge and comfit manufacturer to His Majesty the King', only to finish that course of thought in remembering the English anthem: 'God. Save. Our. Sitting on the throne, sucking red jujubes white'. (144) Thus in the mind of a man whose life is bearable only because it is interesting (and it is interesting mostly because he does not know where his next thought might lead him), God and King are blasphemously being connected by the motif of gluttony. Blasphemy, however, does not end there: gluttony will quickly turn into bloodthirstiness, when a member of Y.M.C.A shoves a leaflet with the words 'washed in the blood of lamb' into Bloom's hand. Then Bloom starts thinking about bloodthirstiness of the state and the church: 'Birth, hymen, martyr, war, foundation of a building, sacrifice, kidney burntoffering, druids' altars. (144) The Lestrygonians from the assumed title of this episode thus attain an unexpected contemporary incarnation, while Bloom's affection for food turns into repulsion over cannibalism.

Therefore, the permanent disgust that Stephen Dedalus feels towards the overall spiritual baseness of the world, seems to have its counterpart in Bloom's repugnance over certain physical aspects of that world. If Bloom and Stephen are, as some critics say, the body and spirit of one being, ${ }^{3}$ then during Bloom's lunch that being feels a strong urge to throw up. There is no help from an altruistic gesture towards animals as a feeble attempt to change the course of his thoughts: Bloom throws pieces of cake to the seagulls, but their rapaciousness reminds him of the

\footnotetext{
${ }^{2}$ In book 10 of The Odyssey, Odysseus and his men reach the island of the Lestrygonians, whose king is a giant and a cannibal, who eats many members of the crew and leads his people in the attack upon the surviving ones. Odysseus manages to escape, with a part of his crew.

3 See, for example, Richard Ellmann, Ulysses on the Liffey, Oxford University Press, Oxford, 1972, pp. 74-77.
} 
fact that those birds are not romantic wanderers, but carriers of horrible infective diseases. And then, in his irreversible metonymical stream of consciousness, he thinks about venereal diseases and, consequently, about the possibility that his wife is at that very moment being infected with some of them in the encounter with her lover, Boylan.

After such thoughts, who would care about going to lunch? Only a person who has to, so as not to die of hunger, or someone who does not know what to do with himself - like Bloom, in his futile attempts to escape from lascivious images produced by his own imagination, with his beloved, sensitive wife Molly and the vulgar, cruel Blazes Boylan as the main protagonists. Things will not get any better with his entrance into a restaurant, where immediately upon arrival he sees the following scene:

Men, men, men.

Perched on high stools by the bar, hats shoved back, at the tables calling for more bread no charge, swilling, wolfing gobfuls of sloppy food, their eyes bulging, wiping wetted moustaches. (...) New set of microbes. A man with an infant's saucestained napkin tucked round him shoveled gurgling soup down his gullet. A man spitting back on his plate: halfmasticated gristle: no teeth to chewchewchew it. ${ }^{4}$

Such spectacle very vividly explains how someone who so thoroughly enjoyed his fried kidneys for breakfast, can feel so strong an impulse to become a vegetarian. Even becoming a vegetarian, however, cannot be a solution at that point: Bloom has reached such a high degree of repulsion towards any kind of food, that he cannot stand the smell of onions.

Rejection of food is one of the few ways of self-destruction that can be related to Leopold Bloom, whose insatiable lust for life defies all the troubles that fate so lavishly puts in his way: it is as if his father's suicide, the death of his newborn son and slow decay of his marriage only strengthen his awareness of the singularity and preciousness of life. The moments that precede his lunch on that day are the moments of crisis and hesitation, in which with his nihilistic disgust over the sordidness of human nature he closely approaches attitudes similar to those of Stephen Dedalus. That is why the medicine he reaches for is quite in accordance with such disposition: like Stephen, who tries to wash away his repugnance over the world with alcohol (succeeding only in augmenting it, of course), Bloom leaves the restaurant as the site of hideous human gluttony and

4 Ulysses, p.161. 
goes into a pub, where he orders a glass of burgundy wine. Along the way, he resists the temptation to order sardines: in that resistance, he is helped by the first sip of wine, but also by the memory of the nickname 'Mackerel', that he carried in his childhood: eating fish for someone who had such a nickname would be an act of cannibalism. That is why Bloom, whose nature obviously tries to resist Lestrygonian impulses, orders a gorgonzola sandwich. His resistance is further helped by a tender memory of his love with Molly in its early days, and then it becomes clear that his loathing of food is in fact loathing of sexuality. Blazes Boylan has been too much in his thoughts on that day; with Boylan, there went the awareness of Molly's unfaithfulness, and thence the thought of sexual intercourse as something vile and gruesome. Sexuality and hunger are closely connected, both in Homer's tale about Lestrygonians and in Bloom's thoughts in Davy Byrne's pub. This is best testified by his memory, that at first seems so romantic:

Glowing wine on his palate lingered swallowed. Crushing in the winepress grapes of Burgundy. (...) Hidden under wild ferns on Howth. Below us bay sleeping sky. No sound. The sky. The bay purple by the Lion's head. (...) Cool with soft ointments her hand touched me, caressed: her eyes upon me did not turn away. Ravished over her I lay, full lips full open, kissed her mouth. Yum. Softly she gave me in my mouth the seedcake warm and chewed. Mawkish pulp her mouth had mumbled sweet and sour with warm, sticky gumjelly lips. (...) Hot I tongued her. She kissed me. I was kissed. All yielding she tossed my hair. Kissed, she kissed me.

Me. And me now.

Stuck, the flies buzzed. ${ }^{5}(167-168)$

Bloom is, therefore, trying to escape from vulgar and obscene connotations of food into a romantic memory from long ago, only to find the same aggressive sexuality at its end, followed by a heartbreaking conclusion that he is quite helpless in front of it - especially when it concerns his own marriage. In addition to that, he is being mocked by two flies copulating on the windowpane, and so he quickly swallows the last bits of his so demonstratively asexual sandwich and hurries to the street, fleeing from every possible thought of food and its symbolical meanings. However, the first person he meets upon going out of the pub is Blazes Boylan, a

${ }^{5}$ Ibid., pp. 167-168. 
lighthearted cannibal whose prey for that afternoon is none else but Mrs. Bloom. Vegetarianism, Bloom realizes at that very moment, may not be the most effective medicine against marital unfaithfulness. Without proper reason and without any effect, he has deprived himself of a proper meal, remaining halfway hungry after that unwanted gorgonzola sandwich, with his dinner so distant somewhere in that day. The only thing more distant than that dinner is Molly's bed, inaccessible and chimerical like Ithaca.

\section{References}

Ellmann, Richard (1972). Ulysses on the Liffey. Oxford: Oxford UP. Joyce, James (1993). Ulysses. Oxford: Oxford UP. 